\title{
Small-scale spatial heterogeneity in infection levels by symbionts of the amphipod Talorchestia quoyana (Talitridae)
}

\author{
Robert Poulin*, Stephen R. Rate \\ Department of Zoology, University of Otago, PO Box 56, Dunedin, New Zealand
}

\begin{abstract}
The beach hopper amphipod Talorchestia quoyana is not distributed homogeneously in its sandy beach habitat, but instead occurs in dense patches under large pieces of tidal debris. This marked patchiness on a scale of just a few metres may create a higher level of aggregation among hosts for the symbionts and parasites of beach hoppers. Prevalence of infection by a mermithid nematode parasite varied significantly among 5 beach hopper patches, located within a few hundred metres of one another, on a New Zealand sandy beach. Similarly, the prevalence and mean intensity of infection by rhabditid nematodes and mites also varied significantly among beach hopper patches. This variation is not due to differences in amphipod sizes among patches, as the effect of size was controlled in the analysis. The symbionts and parasites were aggregated among individual amphipods within patches, with rhabditid nematodes also aggregated among patches, reflecting a higher, independent scale of aggregation. There were also positive associations between rhabditid nematodes and both mermithid nematodes and mites across host individuals, suggesting that individual variation among amphipods in susceptibility to symbionts may account for their aggregation within patches. These results indicate that the loosely fragmented distribution of beach hoppers is linked to a higher scale aggregation of their parasites and symbionts, a phenomenon that may impact on their population biology and that of the host.
\end{abstract}

KEY WORDS: Aggregation $\cdot$ Beach hopper $\cdot$ Mite $\cdot$ Mermithidae $\cdot$ Nematode $\cdot$ New Zealand · Rhabditidae $\cdot$ Talitridae

\section{INTRODUCTION}

Parasites and other symbionts are usually aggregated among the individuals in a host population. Even in an evenly dispersed population of genetically homogeneous hosts, stochastic processes will lead to an aggregation of symbionts on relatively few hosts (Anderson \& Gordon 1982, Poulin 1998). The spatial clumping of hosts can influence the aggregated distribution of symbionts, just as differences in the dispersal of infected and uninfected hosts could add a spatial component to symbiont distribution. There are few empirical studies, however, which discuss the link between the

*E-mail: robert.poulin@stonebow.otago.ac.nz spatial structure of host populations and the distribution of symbionts. Even in systems with hosts displaying a loose spatial population structure, with some movements of individuals among patches, differences between patches in infection levels can have immediate effects on the transmission dynamics of the symbionts and host ecology. Differences in infection levels between host patches can result from heterogeneity in environmental conditions and their influence on the survival and transmission of the symbionts' infective stages, and from parasite-induced movements of hosts toward certain habitat patches (e.g. Curtis 1987). There is little information on how host spatial structure influences the aggregation of symbionts, both among host individuals and among host patches. 
The beach hopper amphipod Talorchestia quoyana (family Talitridae) is a common inhabitant of New Zealand's sandy beaches (Morton \& Miller 1973). These nocturnal, semi-terrestrial crustaceans live in burrows and feed on the plant and animal debris brought in by tides and waves. They are not uniformly distributed along the beach, but tend to aggregate under large pieces of debris, such as broken straps of kelp (Inglis 1989, Marsden 1991, Richardson et al. 1991). This creates a marked spatial heterogeneity in the density of beach hoppers on a scale of just a few metres. These aggregations are not permanent, though, with many exchanges of individuals among patches occurring daily. Beach hoppers worldwide are hosts to mites (Kitron 1980, Rigby 1996a,b, Pugh et al. 1997) and nematodes (Marcogliese 1993, Rigby 1996a). T. quoyana is host to a least 3 species of symbionts. The first is a species of mermithid nematode that resembles Thaumamermis cosgrovei, a parasite known from terrestrial isopods (Poinar 1981) and occurring in New Zealand (G. Poinar pers. comm.). Mermithids are large worms that develop to adulthood in an arthropod host, usually killing their host when they emerge. The second species is an unidentified rhabditid nematode, possibly related to the rhabditids found in North American beach hoppers (Rigby 1996a). Third-stage larvae of these worms (but no adults) are found under the dorsal plates of the hoppers' exoskeleton and in their haemocoel; whether they are parasitic or phoretic is not clear. The third symbiont found on $T$. quoyana is the deutonymph stage of the mite Dendrolaelaps sp. (Mesostigmata: Digamasellidae), probably belonging to 1 of the species described by Luxton (1984). These larval mites are phoretic and not parasitic, using hoppers to disperse to other host aggregations.

If all habitat patches are similar, we would expect the distribution of these symbionts to be homogeneous among patches. The aims of this study were to perform preliminary comparisons of infection levels by the 3 species of symbionts in different patches from the same beach hopper population, and to determine whether the 3 species display aggregation among, as well as within, host patches.

\section{METHODS}

Beach hoppers Talorchestia quoyana were collected on 30 November 1999 from Long Beach, just north of Dunedin, South Island, New Zealand. The shore there consists of a sandy beach with a gentle slope and exposed to moderate wave action. Samples were obtained from 5 patches, each found under a pile of stranded kelp and separated from the others by 100 to
$300 \mathrm{~m}$, and all located along the strandline of tidal debris. All patches came from similar locations, with no obvious habitat differences among them. Hoppers were captured by sweeping the top layer of sand into plastic bags, as well as picking up all larger individuals seen moving away.

All amphipods were returned to the laboratory, and kept alive in moist sand until dissection (completed within $36 \mathrm{~h}$ following capture). Some mites may have detached from their host during this period, but counts made on selected individuals at different times suggest that this was not common. Amphipods were classified as juveniles $(\leq 10 \mathrm{~mm})$ or adults, and the sex of adults was determined (males have large specialised gnathopods). The length of each individual was measured from the anterior end of the cephalon to the posterior end of the telson using a micrometer set in a dissecting microscope. The number of mites on each hopper was recorded, as well as the number of rhabditid nematodes in each hopper and whether or not they contained a mermithid nematode. The latter always occurred singly and, when undamaged, they were measured to the nearest millimetre.

All data were log-transformed (but see below) to meet the assumptions of parametric statistical tests prior to analysis. ANCOVAs or Student's $t$-tests were used to test for differences in amphipod lengths or mean infection levels among patches, developmental stages or sexes. $G$-tests of independence were used to compare frequencies of infected and uninfected hosts among patches. Relationships among continuous variables were assessed using regressions or correlations.

Using raw data and variance tests similar to those described by Boulinier et al. (1996), we also determined whether the observed distributions of mites and rhabditid nematodes among amphipods differed from those expected under the null hypothesis that symbionts are distributed among amphipods in a random fashion at both the within-patch and the amongpatch scales. Since the variance-to-mean ratio for a Poisson distribution equals 1, the following chisquare approximation is used to test for a departure of the among-patch variance from that of a random distribution:

$$
\sum_{j=1}^{N}\left(X_{j}-X_{\mathrm{m}}\right)^{2} / X_{\mathrm{m}}
$$

with $N-1$ degrees of freedom; where $N$ is the number of patches, $X_{j}$ is the mean number of symbionts (rhabditid nematodes or mites) per amphipod in Patch $j$, and $X_{\mathrm{m}}$ is the mean number of symbionts per amphipod among all patches pooled. Similarly, the following chisquare approximation is used to test for a departure of the within-patch variance from that of a random distribution: 


$$
\sum_{j=1}^{N} \sum_{i=1}^{n_{j}}\left(x_{i j}-X_{j}\right)^{2} / X_{j}
$$

with $n-N$ degrees of freedom; where $n_{j}$ is the number of amphipods in Patch $j$, and $x_{i j}$ is the number of symbionts found on amphipod $i$ in Patch $j$.

\section{RESULTS}

All 3 symbiont species occurred in all 5 patches sampled (Table 1). The numbers of mites per individual Talorchestia quoyana were low, with only 2 of the 77 mite-infested amphipods harbouring more than 3 mites. Rhabditid nematodes reached much higher numbers in certain hosts, with their distribution following a typical aggregated pattern (Fig. 1).

The numbers of amphipods sampled per patch ranged from 57 to 99 , with the relative numbers of juveniles and adult females and males also varying among patches (Table 1). Males are generally larger than females, with both adult sexes larger than juveniles. For this reason, there were significant differences in the average length of hoppers among patches $\left(F_{4,356}=14.6, p=0.0001\right)$. Separate analyses were performed including adult amphipods only; they gave results identical to those of analyses including juveniles, and only the latter are reported here. Amphipods harbouring mermithids were on average longer than those not parasitised by mermithids $(t=3.159$, $\mathrm{df}=359$, $\mathrm{p}=0.0017)$; in addition, among infected amphipods, the length of the mermithid parasite (range 15.5 to $185.6 \mathrm{~mm})$ correlated positively with host length $(\mathrm{r}=$ $0.561, \mathrm{n}=29, \mathrm{p}=0.0015)$. Amphipod length correlated positively with both numbers of rhabditid nematodes per host ( $\mathrm{r}=0.265, \mathrm{n}=361, \mathrm{p}=0.0001)$ and numbers of mites per host $(\mathrm{r}=0.284, \mathrm{n}=361, \mathrm{p}=0.0001)$ although there was much scatter in the plots and these relationships explain only a small proportion of the total variance in infection levels. Amphipod length is nevertheless a correlate of infection by all 3 symbiont species, and its effect was considered in subsequent analyses. Using amphipod length as a covariate in ANCOVAs,

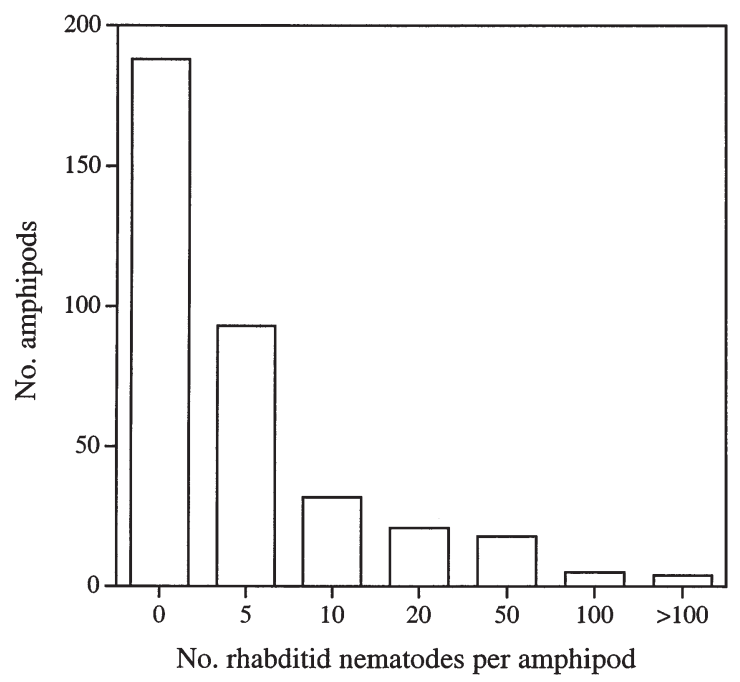

Fig. 1. Frequency distribution of rhabditid nematodes among 361 beach hopper amphipods Talorchestia quoyana

we found that there were differences in numbers of mites per amphipod among juveniles, adult females and adult males, independent of their body sizes $\left(F_{2,358}=9.39, \mathrm{p}=0.0001\right)$; adult males harboured more mites than expected based on their size, and juveniles harboured fewer than expected. There was no such pattern with respect to rhabditid nematodes $\left(F_{2,358}=\right.$ 0.09, $\mathrm{p}=0.914$ ).

The most interesting comparison is that among the 5 patches. The frequencies of infected and uninfected amphipods varied significantly among patches, for all 3 symbiont species (mermithids: $G=9.324, \mathrm{df}=4, \mathrm{p}=$ 0.0535 ; rhabditid nematodes: $G=57.876$, df $=4, \mathrm{p}=$ 0.0001; mites: $G=46.451$, df $=4, \mathrm{p}=0.0001$ ). Infection by the 3 symbionts was generally less common among hoppers from Patches 2 and 3 than hoppers from the other patches (Table 1). These differences extend to mean numbers of symbionts per host. Using ANCOVAs with amphipod length as a covariate, there were significant differences among patches in numbers of rhabditid nematodes per host $\left(F_{4,356}=15.609\right.$, $\mathrm{p}=0.0001)$ and in numbers of mites per host $\left(F_{4,356}=\right.$

Table 1. Talorchestia quoyana. Composition, mean length and infection characteristics of beach hoppers from different patches sampled at Long Beach, near Dunedin, New Zealand

\begin{tabular}{|c|c|c|c|c|c|c|}
\hline \multirow{2}{*}{ Patch } & \multirow[t]{2}{*}{$\mathrm{n}$} & \multirow{2}{*}{$\begin{array}{l}\text { Numbers of juveniles, } \\
\text { females, males }\end{array}$} & \multirow{2}{*}{$\begin{array}{l}\text { Length, mm } \\
(\text { mean } \pm \mathrm{SE})\end{array}$} & \multicolumn{3}{|c|}{ Numbers (\%) harbouring } \\
\hline & & & & Mites & Mermithids & Rhabditids \\
\hline 1 & 99 & $25,46,28$ & $11.0 \pm 0.3$ & $22(22.2)$ & $14(14.1)$ & $35(35.4)$ \\
\hline 2 & 64 & $9,40,15$ & $11.3 \pm 0.3$ & $4(6.3)$ & $2(3.1)$ & $22(34.4)$ \\
\hline 3 & 71 & $44,23,4$ & $8.2 \pm 0.4$ & $3(4.2)$ & $3(4.2)$ & $22(31.0)$ \\
\hline 4 & 70 & $23,28,19$ & $10.9 \pm 0.5$ & $28(40.0)$ & $8(11.4)$ & $48(68.6)$ \\
\hline 5 & 57 & $32,15,10$ & $8.4 \pm 0.5$ & $20(35.1)$ & $6(10.5)$ & $46(80.7)$ \\
\hline
\end{tabular}



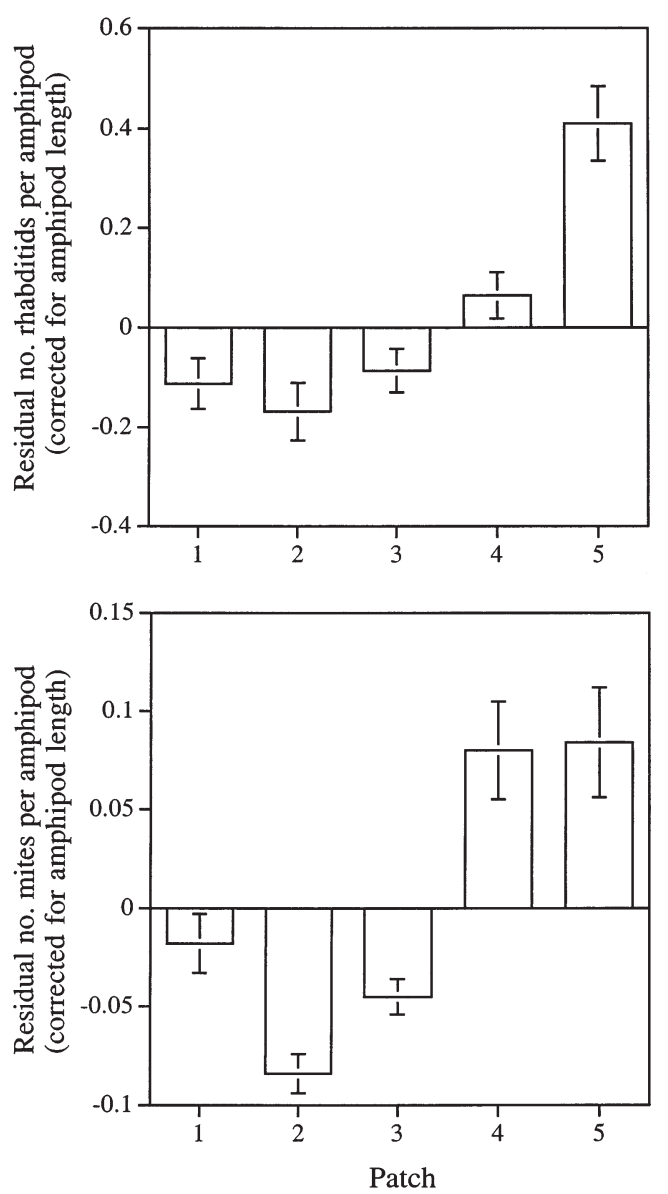

Fig. 2. Mean number $( \pm \mathrm{SE})$ of rhabditid nematodes and mites per amphipod in each of 5 patches of the beach hopper Talorchestia quoyana. Comparisons are made using the residuals of a regression of either rhabditid nematode numbers or mite numbers against amphipod length (from the ANCOVAs)

$15.617, \mathrm{p}=0.0001)$. Infection levels generally appear to be higher in Patches 4 and 5 than what one would expect based on the body sizes of the amphipods from these patches (Fig. 2).

The variance tests revealed that for rhabditid nematodes both the among-patch $\left(\chi^{2}=18.61, \mathrm{df}=4, \mathrm{p}<0.001\right)$ and the within-patch $\left(\chi^{2}=9878.3, \mathrm{df}=356, \mathrm{p}<0.001\right)$ variances departed from those expected under the null hypothesis. In other words, rhabditid nematodes were aggregated both within and among patches. For mites, only the within-patch variance $\left(\chi^{2}=725.4, \mathrm{df}=356, \mathrm{p}<\right.$ $0.001)$ departed from random, and not the among-patch variance $\left(\chi^{2}=1.32, \mathrm{df}=4\right.$, not significant).

There were some associations between the symbiont species. When correcting for amphipod length in a multiple regression, numbers of rhabditid nematodes correlated positively with numbers of mites per amphipod $(\mathrm{r}=0.214, \mathrm{n}=361, \mathrm{p}=0.0001)$. Thus, independent of their size, amphipods that harboured many rhabdi- tid nematodes also tended to harbour mites. After correcting for host length, amphipods harbouring mermithids harboured more rhabditid nematodes than amphipods not infected by mermithids $(t=3.314$, df $=$ $359, \mathrm{p}=0.001$ ); there were no differences in numbers of mites between amphipods with and without mermithids $(t=0.02, \mathrm{df}=359, \mathrm{p}=0.985)$.

\section{DISCUSSION}

The insular nature of hosts as habitats means that symbionts exploit a physically fragmented habitat even in evenly distributed host populations. If hosts are patchily distributed in space, the habitat of symbionts becomes fragmented on a higher scale, with possible consequences for their epidemiology and their effects on the host population. Here we showed that 3 species of symbionts of the amphipod Talorchestia quoyana all show significantly heterogeneous distributions both within and among (except mites) high-density patches of hosts. These host patches persist for some time but with many exchanges of individuals among them, such that we would expect the abundance of symbionts to be roughly homogeneous. The amphipod population appears to consist of a mosaic of infection foci of varying intensity, suggesting that survival or transmission of infective stages are higher in some patches than in others, or that symbionts alter the migration of hosts among patches.

To our knowledge, this is the first report of a mermithid nematode parasitising a talitrid amphipod. The prevalence of mermithids was 2- to 3-fold higher in certain amphipod patches than in others. Mermithids are usually parasitic in insects, in which they develop to large sizes before emerging from the host. They almost invariably cause the death of their host upon emergence (Poinar 1983); Thaumamermis cosgrovei is no exception, with the isopod host dying soon after the exit of the worm (Poinar 1981). Adult worms mate after leaving their hosts. Since mermithids can alter the behaviour of their insect hosts to make them visit areas that are suitable for the survival of adult worms (Maeyama et al. 1994, Vance 1996), it is possible that the worm species in this study induces amphipods to migrate to patches where the conditions (e.g. humidity) are favourable to its survival. Also, uninfected hoppers may be selected to avoid these patches, since the sand under them is likely to contain much more infective mermithid larvae (a lethal parasite) than the sand of other patches.

Rhabditid nematodes and mites follow the trend reported in other studies with respect to their occurrence on talitrid amphipods of different sizes: larger amphipods harbour more nematodes and/or mites 
(e.g., Rigby 1996a,b). However, we found that adult male amphipods harboured greater mite loads than did females, whereas other studies have reported higher mite loads on females than on males (Kitron 1980) or no differences between the sexes (Pugh et al. 1997). The significant variation in prevalence and abundance of rhabditid nematodes and mites among amphipod patches may have important consequences for the dynamics of these symbionts, but it may have little impact on the host population. Mites initially thought to be parasitic on talitrid amphipods (Kitron 1980) in fact use them for dispersal only (Rigby 1996a,b, Pugh et al. 1997); this is true of our species as well. The status of the rhabditid nematodes is less clear. Rigby (1996a) found such nematodes living under the edges of the dorsal pereonites of beach hoppers' exoskeletons in North America. He suggests that these nematodes are probably phoretic and not parasitic. In our specimens, the nematodes were found beneath the exoskeleton, living in the amphipod's haemocoel. If they were parasitic, however, we should have found adults and not only third-stage larvae. The likely effect of this nematode species on host fitness is thus unclear.

Rigby (1996a) reports a negative relationship between the number of mites per host and the number of rhabditid nematodes per host, after controlling for amphipod body size. His results suggest that some form of interspecific competition is taking place between these symbionts on beach hoppers. In contrast, we found a positive association between numbers of these 2 symbionts, and between the occurrence of mermithid and rhabditid nematodes. This suggests that there may be variability among individual beach hoppers in susceptibility to the various symbionts, such that a predisposition for infection by one symbiont may also mean high susceptibility to the other symbionts. The significant heterogeneity in symbiont numbers resulting in their aggregation within patches may thus in part reflect heterogeneity among individuals. The variations among patches are more likely the product of stochastic transmission processes or differences between patch characteristics, such as absolute amphipod density, proportion of juveniles, sex ratio, kelp age, humidity, salinity or sand grain size (e.g. Bowers 1964, Inglis 1989). One or more of these variables may explain why certain patches (i.e. 2 and 3) were 'poor' patches for all 3 symbiont species (see Table 1 \& Fig. 2).

Almost all studies of the effects of parasites on amphipods have investigated the influence of acanthocephalan or trematode parasites on amphipods of the family Gammaridae. These studies have identified important effects on host reproductive output and survivorship (e.g., Thomas et al. 1995a,b, Bakker et al.
1997, Dezfuli et al. 1999). Similar information will be required for the symbionts of Talorchestia quoyana. Still, the results of this study show that spatial heterogeneity can exist in symbiont abundance even in a host population with a high degree of inter-patch fluidity. The impact of the higher scale aggregation of parasites and symbionts reported here on the movements, patch choice and dynamics of beach hoppers remains to be assessed. Another important implication of our results is that proper estimates of the prevalence or abundance of symbionts in a fragmented host population require samples from several host patches, even if only on a scale of metres.

Acknowledgements. We thank Aroha Miller and Maya Steeper for assistance in the field and laboratory. Invaluable assistance with the identification of parasites and symbionts was provided by Heather Proctor (Griffith University, Queensland) for mites, Brad Hyman (University of California, Riverside) and George Poinar (Oregon State University) for mermithid nematodes, and Serge Morand (Université de Perpignan) and Martin Adamson (University of British Columbia) for rhabditid nematodes.

\section{LITERATURE CITED}

Anderson RM, Gordon DM (1982) Processes influencing the distribution of parasite numbers within host populations with special emphasis on parasite-induced host mortalities. Parasitology 85:373-398

Bakker TCM, Mazzi D, Zala S (1997) Parasite-induced changes in behavior and color make Gammarus pulex more prone to fish predation. Ecology 78:1098-1104

Boulinier T, Ives AR, Danchin E (1996) Measuring aggregation of parasites at different host population levels. Parasitology 112:581-587

Bowers DE (1964) Natural history of two beach hoppers of the genus Orchestoidea (Crustacea: Amphipoda) with reference to their complemental distribution. Ecology 45: 677-696

Curtis LA (1987) Vertical distribution of an estuarine snail altered by a parasite. Science 235:1509-1511

Dezfuli BS, Rossetti E, Bellettato CM, Maynard BJ (1999) Pomphorhynchus laevis in its intermediate host Echinogammarus stammeri in the River Brenta, Italy. J Helminthol 73:95-102

Inglis G (1989) The colonization and degradation of stranded Macrocystis pyrifera by the macrofauna of a New Zealand sandy beach. J Exp Mar Biol Ecol 125:203-217

Kitron UD (1980) The pattern of infestation of the beachhopper amphipod Orchestoidea corniculata, by a parasitic mite. Parasitology 81:235-249

Luxton M (1984) New species of intertidal Mesostigmata (Acari) from New Zealand. Rec Auck Inst Mus 21:83-100

Maeyama T, Terayama M, Matsumoto T (1994) The abnormal behavior of Colobopsis sp. (Hymenoptera: Formicidae) parasitized by Mermis (Nematoda) in Papua New Guinea. Sociobiology 24:115-119

Marcogliese DJ (1993) Larval parasitic nematodes infecting marine crustaceans in Eastern Canada. 1. Sable Island, Nova Scotia. J Helminthol Soc Wash 60:96-99

Marsden ID (1991) Kelp sandhopper interactions on a sand 
beach in New Zealand. 1. Drift composition and distribution. J Exp Mar Biol Ecol 152:61-74

Morton JE, Miller MC (1973) The New Zealand sea shore, 2nd edn. Collins, London

Poinar GO Jr (1981) Thaumamermis cosgrovei n. gen., n. sp. (Mermithidae: Nematoda) parasitizing terrestrial isopods (Isopoda: Oniscoidea). Syst Parasitol 2:261-266

Poinar GO Jr (1983) The natural history of nematodes. Prentice Hall, Englewood Cliffs, NJ

Poulin R (1998) Evolutionary ecology of parasites: from individuals to communities. Chapman \& Hall, London

Pugh PJA, Llewellyn PJ, Robinson K, Shackley SE (1997) The associations of phoretic mites (Acarina: Chelicerata) with sand-hoppers (Amphipoda: Crustacea) on the South Wales coast. J Zool (Lond) 243:305-318

Richardson AMM, Swain R, Smith SJ (1991) Local distributions of sandhoppers and landhoppers (Crustacea, Amphipoda, Talitridae) in the coastal zone of western Tasmania. Hydrobiologia 223:127-140

Editorial responsibility: Otto Kinne (Editor),

Oldendorf/Luhe, Germany
Rigby MC (1996a) The epibionts of beach hoppers (Crustacea: Talitridae) of the North American Pacific coast. J Nat Hist 30:1329-1336

Rigby MC (1996b) Association of a juvenile phoretic uropodid mite with the beach hopper Traskorchestia traskiana (Stimpson, 1857) (Crustacea: Talitridae). J Nat Hist 30: $1617-1624$

Thomas F, Lambert A, De Meeüs $T$, Cézilly F, Renaud F (1995a) Influence of Microphallus hoffmanni (Trematoda, Microphallidae) on the survival, sexual selection, and fecundity of Gammarus aequicauda (Amphipoda). Can J Zool 73:1634-1639

Thomas F, Renaud F, Rousset F, Cézilly F, De Meeüs T (1995b) Differential mortality of two closely related host species induced by one parasite. Proc R Soc Lond Ser B Biol Sci 260:349-352

Vance SA (1996) Morphological and behavioural sex reversal in mermithid-infected mayflies. Proc R Soc Lond Ser B Biol Sci 263:907-912

Submitted: February 28, 2000; Accepted: August 22, 2000 Proofs received from author(s): February 13, 2001 